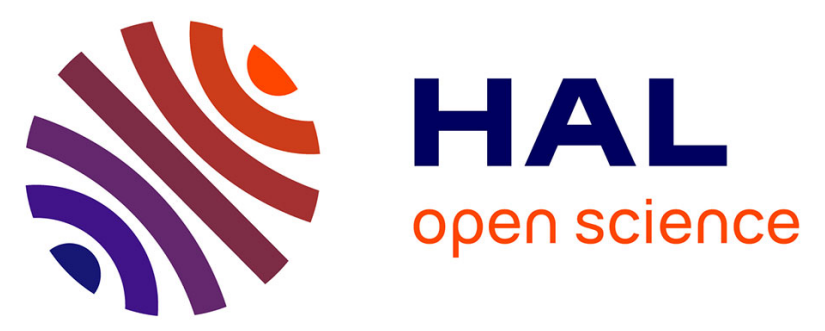

\title{
Five-year outcome for women randomised in a phase III trial comparing doxorubicin and cyclophosphamide with doxorubicin and docetaxel as primary medical therapy in early breast cancer: an Anglo-Celtic Cooperative Oncology Group Study
}

Janine L. Mansi, Ann Yellowlees, Julian Lipscombe, Helena M. Earl, David A.

Cameron, Robert E. Coleman, Timothy Perren, Christopher J. Gallagher, Mary Quigley, John Crown, et al.

\section{To cite this version:}

Janine L. Mansi, Ann Yellowlees, Julian Lipscombe, Helena M. Earl, David A. Cameron, et al.. Fiveyear outcome for women randomised in a phase III trial comparing doxorubicin and cyclophosphamide with doxorubicin and docetaxel as primary medical therapy in early breast cancer: an Anglo-Celtic Cooperative Oncology Group Study. Breast Cancer Research and Treatment, 2010, 122 (3), pp.787794. 10.1007/s10549-010-0989-6 . hal-00547975

\section{HAL Id: hal-00547975 \\ https://hal.science/hal-00547975}

Submitted on 18 Dec 2010

HAL is a multi-disciplinary open access archive for the deposit and dissemination of scientific research documents, whether they are published or not. The documents may come from teaching and research institutions in France or abroad, or from public or private research centers.
L'archive ouverte pluridisciplinaire HAL, est destinée au dépôt et à la diffusion de documents scientifiques de niveau recherche, publiés ou non, émanant des établissements d'enseignement et de recherche français ou étrangers, des laboratoires publics ou privés. 


\title{
Five-year outcome for women randomised in a phase III trial comparing doxorubicin and cyclophosphamide with doxorubicin and docetaxel as primary medical therapy in early breast cancer: an Anglo-Celtic Cooperative Oncology Group Study
}

\author{
Janine L. Mansi • Ann Yellowlees · Julian Lipscombe • Helena M. Earl • \\ David A. Cameron • Robert E. Coleman • Timothy Perren • Christopher J. Gallagher • \\ Mary Quigley · John Crown • Alison L. Jones • Martin Highley • \\ Robert C. F. Leonard • T. R. Jeffry Evans
}

Received: 2 March 2010/Accepted: 5 June 2010/Published online: 18 June 2010

(C) Springer Science+Business Media, LLC. 2010

\begin{abstract}
To compare the long-term outcome of women with primary or locally advanced breast cancer randomised to receive either doxorubicin and cyclophosphamide (AC) or doxorubicin and docetaxel (AD) as primary chemotherapy. Eligible patients with histologic-proven breast cancer with primary tumours $\geq 3 \mathrm{~cm}$, inflammatory or

Preliminary results presented in part at the 38th Annual Meeting of the American Society of Clinical Oncology, Orlando, FL, May 18-21, 2002; completed first analysis presented in part at the 40th Annual Meeting of the American Society of Clinical Oncology, New Orleans, LA, June 5-8, 2004, and published in the Journal of Clinical Oncology 23: 2988-2995, 2005. This 5-year outcome analysis was presented in part at the 44th Annual Meeting of the American Society of Clinical Oncology, Chicago, IL, 2008.
\end{abstract}

This study is conducted on behalf of the Anglo-Celtic Cooperative Oncology Group.

\section{J. L. Mansi $(\bowtie)$}

Department of Medical Oncology, Guy's and St Thomas' Hospital, Guy's and St Thomas' Foundation Trust and King's College London Biomedical Research Centre, 4th Floor, Bermondsey Wing, Great Maze Pond, London SE1 9RT, UK e-mail: Janine.mansi@gstt.nhs.uk; janine@lucia2.demon.co.uk

A. Yellowlees

Quantics Consulting Ltd, Melrose TD6 0SG, UK

J. Lipscombe

ISD Cancer Clinical Trials Team, Edinburgh EH12 9EB, UK

H. M. Earl

University of Cambridge Department of Oncology, and NIHR Cambridge Biomedical Research Centre, Addenbrooke's

Hospital, Cambridge CB2 2QQ, UK

D. A. Cameron

NCRN Co-ordinating Centre, Leeds LS2 9LS, UK locally advanced disease, and no evidence of distant metastases, were randomised to receive a maximum of 6 cycles of either doxorubicin $\left(60 \mathrm{mg} / \mathrm{m}^{2}\right)$ plus cyclophosphamide $\left(600 \mathrm{mg} / \mathrm{m}^{2}\right) \mathrm{i} / \mathrm{v}$ or doxorubicin $\left(50 \mathrm{mg} / \mathrm{m}^{2}\right)$ plus docetaxel $\left(75 \mathrm{mg} / \mathrm{m}^{2}\right) \mathrm{i} / \mathrm{v}$ every 3 weeks, followed by surgery on completion of chemotherapy. Clinical and pathologic responses have previously been reported. Time to relapse, site of relapse, and all-cause mortality were recorded. This updated analysis compares long-term disease-free (DFS) and overall survival (OS) using stratified log rank methods. A total of 363 patients were randomised to $\mathrm{AC}(n=181)$ or $\mathrm{AD}(n=182)$. A complete pathologic response was observed in $16 \%$ for $\mathrm{AC}$ and $12 \%$ for $\mathrm{AD}$ $(P=0.43)$. The number of patients with positive axillary nodes at surgery with AC was $61 \%$ and AD $66 \%$ $(P=0.36)$. At a median follow-up of 99 months there is

\section{R. E. Coleman}

Academic Unit of Clinical Oncology, Weston Park Hospital, Sheffield S10 2SJ, UK

T. Perren

St James' University Hospital, Leeds LS9 7TF, UK

C. J. Gallagher

Department of Medical Oncology, St Bartholomew's Hospital, London EC1A 7BE, UK

M. Quigley

Queens Hospital, Romford RM7 0AG, UK

J. Crown

Department of Medical Oncology, St Vincent's University

Hospital, Dublin 4, Ireland 
no significant difference between the two groups for DFS $(P=0.20)$ and $\mathrm{OS}(P=0.24)$. Deaths were due to metastatic breast cancer in $96 \%$ of patients. Our data do not support a clinical benefit for simultaneous administration of $\mathrm{AD}$ compared with AC. However, the data do not exclude a smaller benefit than the study was powered to detect and are consistent with an increase in both diseasefree and overall survival of about $5 \%$ for $\mathrm{AD}$ compared with AC. Outcome is consistent with the pathologic complete response following surgery.

Keywords Breast cancer - Neoadjuvant therapy · Docetaxel - Outcome

\section{Introduction}

We have previously reported on the clinical and pathologic response rates for patients with large primary, inflammatory, or locally advanced breast cancers receiving a combination of doxorubicin with cyclophosphamide (AC) compared with doxorubicin and docetaxel (AD) as primary medical therapy [1]. The rationale for this study was based on the increasing use of primary chemotherapy in women with locally advanced or large primary $(\geq 3 \mathrm{~cm})$ breast cancers with the aim of reducing the size of the primary tumour. This had been shown to increase the rate of breast conservation surgery and to avoid the need for mastectomy in selected patients. The hypothesis was also that there may be an improvement in DFS and OS by abolishing micrometastatic disease [2, 3]. High response rates (60-90\%) had been reported with primary chemotherapy in large operable breast cancers, suggesting that early breast cancer is clinically more chemo-sensitive than metastatic disease [4-7]. Furthermore, improved outcome (overall survival) is related to higher clinical and pathologic response rates to primary chemotherapy [6-10].

Various chemotherapy regimens have been used as primary chemotherapy in women with breast cancer. Most

\author{
A. L. Jones \\ Department of Medical Oncology, Royal Free Hospital \\ and University College London Biomedical \\ Research Centre, London NW3 2QT, UK \\ M. Highley \\ Plymouth Oncology Centre, Derriford Hospital, \\ Plymouth PL6 8DH, UK \\ R. C. F. Leonard \\ Department of Cancer Services and Clinical Oncology, \\ Charing Cross Hospital, London W6 8RF, UK
}

T. R. Jeffry Evans

University of Glasgow, Beatson West of Scotland Cancer

Centre, 1053 Great Western Road, Glasgow G12 OYN, UK regimens incorporate an anthracycline which generally produce an overall objective clinical response in over twothirds of patients and a pathologic complete response (pCR) rate of $10-15 \%[5,11]$. At the time of development of this study, docetaxel had been shown to have significant activity in patients with metastatic breast cancer, including those patients with anthracycline-resistant disease [12, 13]. The single-agent activity of docetaxel and of the anthracyclines, and the absence of complete cross-resistance between them, provided a rationale to develop these drugs in combination in patients with breast cancer [14]. Furthermore, $\mathrm{AD}$ gave superior response rates and time to progression, but not superior OS, compared with AC as first-line chemotherapy in patients with metastatic breast cancer. This was published shortly after recruitment into our study was completed [15].

We previously reported a trend towards a superior clinical response rate with $\mathrm{AD}$ compared with $\mathrm{AC}$ which did not reach statistical significance, and also did not show an advantage of $\mathrm{AD}$ over $\mathrm{AC}$ in terms of the pathologic response rate. However, at the time of reporting, the median DFS and OS had not been reached. We now report the outcome of these patients after a median follow-up of 99 months.

\section{Methods}

\section{Patient eligibility}

This was a phase III, multicentre, randomised trial involving 23 centres in the UK, Ireland and Belgium. The Local Research Ethics Committee of each participating institution approved the study, and all patients gave written, informed consent before any study-related procedures were performed.

Eligible patients were women with histologic-proven (core biopsy) breast cancer with large primary $(\geq 3 \mathrm{~cm})$ tumours, inflammatory breast cancer, or locally advanced disease who were considered to be candidates for primary chemotherapy prior to surgical intervention. All patients were required to have adequate performance status $(\mathrm{ECOG} \leq 1)$, adequate haematologic $(\mathrm{Hb} \geq 9 \mathrm{~g} / \mathrm{dl}$; absolute neutrophil count $\geq 1.5 \times 10^{9} / 1$; and platelets $\geq 100 \times$ $10^{9} / \mathrm{l}$ ), renal (serum creatinine within normal limits), and liver (AST, ALT, and alkaline phosphatase all $\leq 1.5 \times$ upper limit of normal, and bilirubin within normal limits) function and to have no evidence of metastatic disease. Patients were excluded from the study if there was any evidence of active cardiac disease, prior history of malignancy other than basal cell carcinoma of the skin or in situ cancer of the cervix. 
Study design

All patients had initial chest radiography, electrocardiogram, full blood count, and assessment of renal and liver function prior to study entry. Additional investigations were performed in line with local policy. Patients were stratified according to operability and according to participating centre, and randomised to receive up to a maximum of six cycles of AD or AC. Patients were eligible for the study if they had inoperable disease that might be rendered operable following a good response to primary chemotherapy, or if they were operable but required a mastectomy and desired down-staging to enable breast conserving surgery.

On completion of chemotherapy patients underwent surgery, including axillary node dissection, with the choice of surgical procedure for local control of the primary lesion at the discretion of the surgeons at the participating centre. If a patient had a clinical or radiologic complete response and the investigator determined that no surgery was required then the patient was referred for radiotherapy. Post-operative radiotherapy and tamoxifen were administered as appropriate based on existing management guidelines.

\section{Chemotherapy treatment}

Chemotherapy consisted of either (a) intravenous bolus injections of doxorubicin $\left(60 \mathrm{mg} / \mathrm{m}^{2}\right)$ and cyclophosphamide $\left(600 \mathrm{mg} / \mathrm{m}^{2}\right)$ both administered every 3 weeks (AC); or (b) intravenous bolus injection of doxorubicin $(50 \mathrm{mg} /$ $\mathrm{m}^{2}$ ) and docetaxel $\left(75 \mathrm{mg} / \mathrm{m}^{2}\right)$ administered as a 1 - $\mathrm{h}$ intravenous infusion, with both drugs being given every 3 weeks (AD). The doses of $\mathrm{AD}$ were based on the preliminary recommendations available from the (then unpublished) dose-finding study of this combination in first-line treatment of patients with metastatic breast cancer [14]. The doses of AC were those used in primary chemotherapy studies in breast cancer at that time, both in the USA [16] and UK [17]. Prophylactic antibiotics were given to reduce the risk of neutropenic sepsis with AD. The details of the chemotherapy administration including criteria for dose delays and reductions have been reported previously [1].

Tumour response and outcome measures

Clinical and pathologic tumour response evaluation together with details of dose intensity have also been described previously [1] and are summarised in "Results".

Statistical methods

The primary endpoint of this study was the overall clinical response rate to primary chemotherapy. Response rates and nodal status were compared between the two treatment groups using the $\chi^{2}$ test, excluding unknown values. Confidence intervals for proportions were calculated using the normal approximation to the binomial distribution.

DFS was defined as the time in months from randomisation to first recurrence. If no recurrence was recorded but the patient had died from breast cancer then DFS was defined as the time to death. If no recurrence was recorded and the patient had died from causes other than breast cancer then DFS was censored at the date of death. If no recurrence was recorded and the patient had not died then DFS was censored at the date that the patient was last seen alive.

OS was defined as time in months from randomisation to death from any cause. If the patient had not died then OS was censored at the date that the patient was last seen alive.

DFS and OS were compared using log rank tests stratified by operability. Kaplan-Meier survival curves were plotted, and the 5-year DFS and OS were calculated along with corresponding 95\% confidence intervals. Details of sites of relapse (local only, local and distant, distant) and cause of death (whether or not due to breast cancer; other cause if not due to breast cancer) were recorded for all patients. A Kaplan-Meier analysis of recurrence and death in relation to nodal status, pathologic complete response (pCR), and oestrogen receptor (ER) status was performed to establish consistency of this patient group with the literature. A Cox regression analysis was also performed to enable a comparison of treatments adjusting for prognostic variables (oestrogen receptor status, nodal status and type of chemotherapy).

The sample size was determined as 350 patients to provide $90 \%$ power at the (one sided) $5 \%$ significance level of detecting an improvement in the clinical overall response rate from 70 to $84 \%$ (a relative improvement of $20 \%$ ) with the combination of $\mathrm{AD}$. The study has $80 \%$ power for detecting a $15 \%$ difference in DFS and a $14 \%$ difference in OS. All patients were analysed according to the intention to treat.

Data were collected and managed by the Information and Statistics Division (NHS Scotland) Clinical Trials Team (Edinburgh, UK). All analyses were performed by the Study Statistician (Ann Yellowlees, Helen Brown; Quantics Consulting Ltd, UK), independently of the investigators.

Role of the funding source

The study design was approved by the Anglo-Celtic Cooperative Oncology Group. The funding supported the running of the study through the Edinburgh Clinical Trials Unit and a per-patient fee to the hospital recruiting the 
patient. The funding source had no role in collection, analysis, interpretation, or the writing of the manuscript.

\section{Results}

A total of 363 patients were enrolled in this study between January 1999 and February 2002. One hundred and eightyone patients were randomised to receive AC and one hundred and eighty-two patients to receive AD. The patient characteristics and the management following chemotherapy have been reported previously [1] and are summarised in Table 1 . The median tumour size at presentation was $6 \mathrm{~cm}$.

\section{Clinical and pathologic response}

The clinical and pathologic response rates have been reported [1]. The pathologic complete response rate in the breast (pCR breast) was 24 and $21 \%$ for $\mathrm{AC}$ and $\mathrm{AD}$, respectively $(P=0.61)$. Of note, there were 27 patients with pCR in the breast who had involvement of axillary lymph nodes by invasive carcinoma $(\mathrm{AD}=14, \mathrm{AC}=13$ ). Consequently, the true $\mathrm{pCR}$ rates as defined by the absence of any invasive carcinoma in both the breast and the axilla were 16 and $12 \%(P=0.43)$ for $\mathrm{AC}$ and $\mathrm{AD}$, respectively. Conversely, 61 and $66 \%$ of patients who received $\mathrm{AC}$ and $\mathrm{AD}$, respectively, were node positive after chemotherapy $(P=0.36)$.

Table 1 Patient characteristics

\begin{tabular}{llll}
\hline Characteristic & AC & AD & All patients \\
\hline $\begin{array}{l}\text { Number recruited } \\
\text { Age }\end{array}$ & 181 & 182 & 363 \\
$\quad$ Median & 48 & 49 & 48 \\
Range & $25-73$ & $27-74$ & $25-74$ \\
Operability of tumour (pre-chemotherapy) & & \\
Operable by mastectomy & $141(78 \%)$ & $139(77 \%)$ & $280(77 \%)$ \\
Inflammatory cancer & $26(14 \%)$ & $28(15 \%)$ & $54(15 \%)$ \\
Locally advanced tumour & $14(8 \%)$ & $15(8 \%)$ & $29(8 \%)$ \\
Management following chemotherapy & & \\
Breast conservation & $36(20 \%)$ & $38(21 \%)^{\mathrm{a}}$ & $74(20 \%)$ \\
Mastectomy & $137(76 \%)$ & $132(73 \%)$ & $269(74 \%)$ \\
No surgical intervention & $8(4 \%)$ & $12(7 \%)$ & $20(6 \%)$ \\
Radiotherapy & $149(82 \%)$ & $142(78 \%)$ & $291(80 \%)$ \\
Endocrine therapy & $108(60 \%)^{\mathrm{b}}$ & $120(66 \%)$ & $228(63 \%)$ \\
\hline
\end{tabular}

$A C$ doxorubicin and cyclophosphamide treatment group, $A D$ doxorubicin and docetaxel treatment group

${ }^{\text {a }}$ One patient who had axillary surgery only

b One patient who received endocrine therapy after surgery was not included in the original publication (108 patients received endocrine therapy rather than 107) [1]. This does not affect the interpretation of the results
Chemotherapy details

The chemotherapy details, including toxicity, have also been reported previously [1]. In summary, a mean of 5.5 cycles was received by both the groups and similar number of patients received less than the maximum of 6 cycles in both the groups ( 45 and 43 patients receiving $\mathrm{AC}$ and $\mathrm{AD}$, respectively). Despite prophylactic antibiotics in the $\mathrm{AD}$ arm, episodes of grade 3/4 infection occurred more frequently in the $\mathrm{AD}$ arm (57 vs. 19).

Dose reduction was necessary with $19(1.9 \%)$ cycles of $\mathrm{AC}$ in 9 patients, and $150(15 \%)$ cycles of $\mathrm{AD}$ in 47 patients. In contrast, dose delay was necessary with 97 (9.8\%) cycles of AC in 54 patients, but with only $45(4.5 \%)$ cycles of $\mathrm{AD}$ in 26 patients. However, the dose intensity of each regimen, relative to the planned doses and schedules, was similar in both treatment arms $(\mathrm{AC}=88 \%, \mathrm{AD}=$ $86 \%)$.

\section{Relapse and survival}

With a median follow-up of 99 months, 87/181 (48\%) and $76 / 182(42 \%)$ of patients, treated with $\mathrm{AC}$ and $\mathrm{AD}$, respectively, have relapsed and 71/181 (39\%) and 60/182 (33\%) have died from breast cancer. Of the 226 patients alive at the time of this analysis, all but 5 (1 AC, 4 AD) had follow-up information for 5 or more years. There was no significant difference in the DFS between the two groups $(P=0.20)$ : the 5-year DFS for AC is $54 \%(95 \% \mathrm{CI}$ $46-61 \%$ ), and for $\mathrm{AD}$ is $59 \%$ (95\% CI 51-66\%) (Fig. 1). There was also no significant difference in the rates of relapse at local and/or distant sites between AC and AD (Table 2).

At the time of this analysis, 74 and 63 deaths have been observed in the patients treated with $\mathrm{AC}$ and $\mathrm{AD}$, respectively. The 5-year OS is 67\% (95\% CI 60-74\%) for AC and $72 \%$ (95\% CI 65-78\%) for AD. (Fig. 2) There is no significant difference between the two groups for OS $(P=0.24)$. The cause of death was recorded as being due to metastatic breast cancer in $96 \%$ of patients (Table 2).

The Kaplan-Meier analysis for nodal status, pCR, and ER confirms a poorer prognosis for those patients who are node positive, ER negative, and for those who did not achieve a pCR (Tables 3,4). The Cox regression analysis confirmed that ER and nodal status were independently strongly significant factors for DFS and OS $(P<0.001)$, but chemotherapy regimen was not $(P=0.078$ for DFS; $P=0.191$ for OS).

\section{Discussion}

We were the first to report on a randomised controlled trial comparing the simultaneous administration of AD with a 


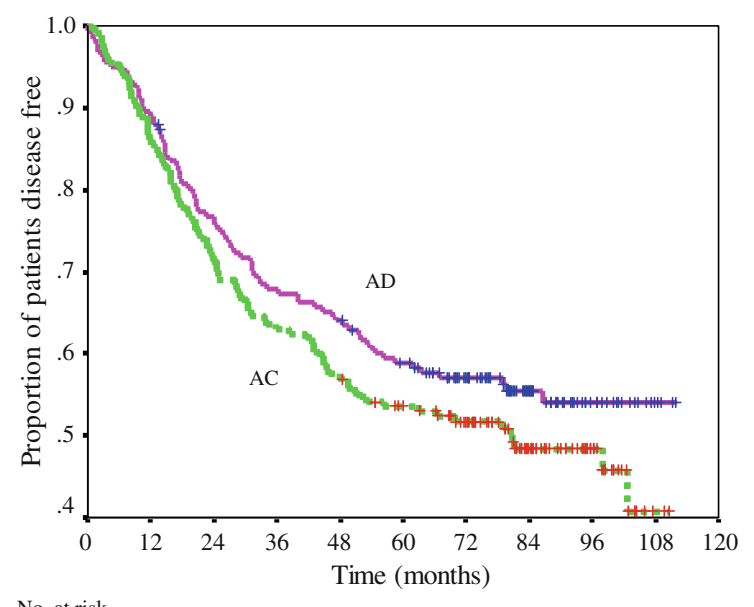

$$
\begin{aligned}
& \begin{array}{lrrrrrrrrrrr}
\text { No. at risk } & & & & & & & & & \\
\text { AC } & 181 & 156 & 129 & 114 & 103 & 92 & 77 & 46 & 22 & 2 & 0 \\
\text { AD } & 182 & 162 & 138 & 122 & 115 & 103 & 82 & 46 & 19 & 4 & 0
\end{array} \\
& \text { Disease-free survival at } 5 \text { years: AC } 0.54 \text { (95\% CI 0.46-0.61), AD } 0.59 \text { (95\% CI 0.51-0.66). }
\end{aligned}
$$
$\mathrm{P}=0.20$

Fig. 1 Kaplan-Meier curve for disease-free survival demonstrating no significant difference $(P=0.20)$ in DFS at 5 years for AC $(54 \%$; $95 \%$ CI $46-61 \%)$ and $\mathrm{AD}(59 \%$; $95 \%$ CI $51-66 \%)$

recognised, anthracycline-containing, standard chemotherapy regimen as primary chemotherapy in patients with large primary or locally advanced breast cancer. The clinical and pathologic response rates were similar for patients receiving either $\mathrm{AC}$ or $\mathrm{AD}$ and comparable to some, but not all, similar studies using these drugs as previously discussed [1].

It is well recognised that outcome following primary medical therapy is related to a number of factors, the most important of which are the presence of positive lymph nodes following chemotherapy and pCR of the primary tumour predicting worse and better outcomes, respectively $[6,8,9,18-21]$. Our data is consistent with the literature in

Table 2 Site of tumour relapse and death

\begin{tabular}{lcc}
\hline Patient treatment & $\begin{array}{l}\mathrm{AC} \\
(N=181) \\
N(\%)\end{array}$ & $\begin{array}{l}\mathrm{AD} \\
(N=182) \\
N(\%)\end{array}$ \\
\hline Site of relapse $^{\mathrm{a}}$ & $22(12)$ & $18(10)$ \\
Local relapse only & $4(2)$ & $2(1)$ \\
Contralateral breast only & $17(9)$ & $14(8)$ \\
Local/contralateral and distant relapse & $44(24)$ & $42(23)$ \\
Distant relapse only & & \\
Cause of death & $74(41)$ & $63(35)$ \\
Total & $71(39)$ & $60(33)$ \\
Metastatic breast cancer & $3(2)$ & $2(1)$ \\
Other & & $1(1)$ \\
Unknown & $0(0)$ & $1(1)$ \\
\hline
\end{tabular}

${ }^{a}$ Patients with recorded relapses

b AC: pulmonary embolus (2), AML: septicaemia, AD: pulmonary embolus, colorectal cancer

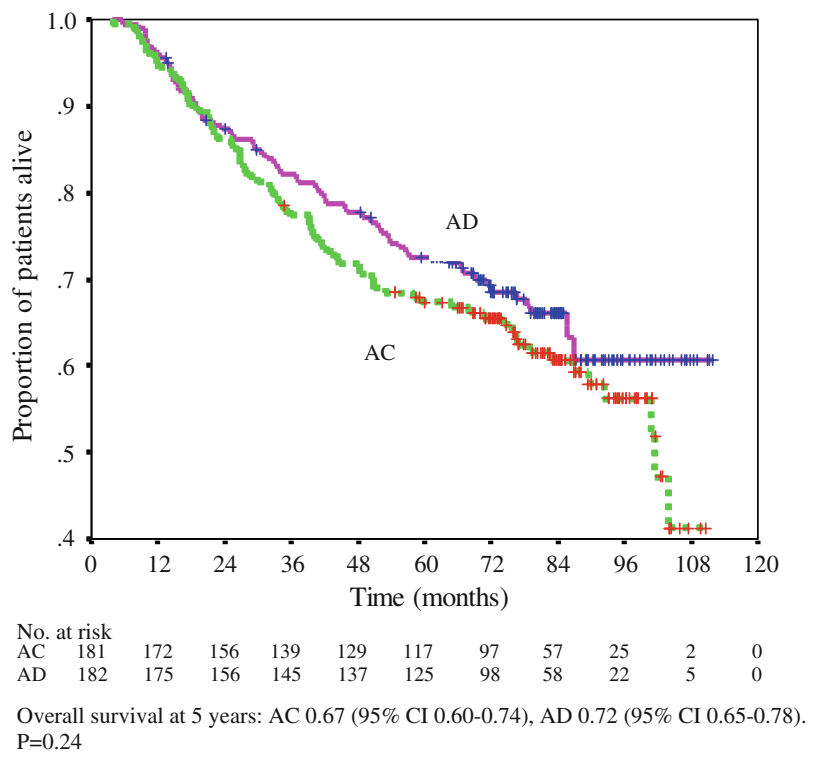

Fig. 2 Kaplan-Meier curve for overall survival demonstrating no significant difference $(P=0.24)$ in OS at 5 years for AC $(67 \% ; 95 \%$ CI $60-74 \%)$ and $\mathrm{AD}(72 \%$; 95\% CI 65-78\%)

terms of these prognostic factors. It is therefore not entirely unexpected that, as there were similar rates of node positivity and pCR following $\mathrm{AC}$ and $\mathrm{AD}$, the outcome was similar in both the groups. The 5-year DFS and OS are comparable with other studies [22,23], particularly as this study group only included patients with tumours of at least $3 \mathrm{~cm}$ (median $6 \mathrm{~cm}$ ). However, it should be noted that this study only had sufficient power to detect differences in outcome of $14 \%$ or more between the treatment groups, and we cannot exclude a smaller benefit than the study was powered to detect. Furthermore, our data are consistent with an increase in both disease-free and overall survival of about $5 \%$ for $\mathrm{AD}$ compared with $\mathrm{AC}$.

The local recurrence rates are high in this study but the patient group consisted of women presenting with locally advanced tumours with a median size of $6 \mathrm{~cm}$ and all of whom would have required a mastectomy at presentation.

To further support these findings, a large adjuvant study using the same combinations albeit with a lower dose of docetaxel $\left(60 \mathrm{mg} / \mathrm{m}^{2}\right)$ reported no difference in outcome for the 2,882 patients enrolled in the study after a median follow-up of 79.5 months (E2197 Intergroup Trial) [23]. Furthermore, a meta-analysis of randomised trials using taxane-based combinations as adjuvant or primary medical chemotherapy for early breast cancer was recently published [24]. This meta-analysis included 13 studies ( $n=22,903$ patients) in which a sensitivity analysis suggested that taxanes given in combination with anthracyclines did not significantly improve OS.

Conversely, there have been several reports on the use of sequential non-cross-resistant chemotherapy; notably, 
Table 3 Kaplan-Meier analysis by clinical variables

\begin{tabular}{|c|c|c|c|c|c|c|c|c|}
\hline \multirow[t]{3}{*}{ Factor } & \multirow[t]{3}{*}{ Level } & \multirow[t]{3}{*}{$N$} & \multicolumn{3}{|c|}{ Relapse } & \multicolumn{3}{|c|}{ Death } \\
\hline & & & \multicolumn{2}{|c|}{ Events } & \multirow{2}{*}{$\begin{array}{l}P \text { (difference } \\
\text { between factor levels) }\end{array}$} & \multicolumn{2}{|c|}{ Events } & \multirow{2}{*}{$\begin{array}{l}P \text { (difference between } \\
\text { factor levels) }\end{array}$} \\
\hline & & & $n$ & $\%$ & & $n$ & $\%$ & \\
\hline Node & $+\mathrm{ve}$ & 212 & 117 & 55 & & 97 & 46 & \\
\hline Status & $-v e$ & 121 & 36 & 30 & & 23 & 19 & \\
\hline Total & & 333 & & & $<0.001$ & & & $<0.001$ \\
\hline \multirow[t]{2}{*}{$\mathrm{pCR}$} & $\mathrm{N}$ & 284 & 141 & 50 & & 110 & 39 & \\
\hline & $\mathrm{Y}$ & 47 & 12 & 26 & & 10 & 21 & \\
\hline Total & & 313 & & & 0.004 & & & 0.031 \\
\hline ER & $-v e$ & 104 & 63 & 61 & & 52 & 50 & \\
\hline Status & $+\mathrm{ve}$ & 222 & 88 & 40 & & 67 & 30 & \\
\hline Total & & 326 & & & $<0.001$ & & & $<0.001$ \\
\hline
\end{tabular}

$p C R$ pathological complete response rate, $E R$ oestrogen receptor

Table 4 Cox regression analysis by clinical variables

\begin{tabular}{lrr}
\hline Factor & Relapse & \multicolumn{1}{c}{ Death } \\
\hline ER & $<0.001$ & $<0.001$ \\
Nodal status & $<0.001$ & $<0.001$ \\
Treatment regimen & 0.078 & 0.191 \\
\hline
\end{tabular}

$E R$ oestrogen status

all show an increased pathologic response rate with this approach $[22,25,26]$. For example, in the NSABP B27 study the pCR rate was increased from $13.7 \%$ following four courses of AC to $26.1 \%$ when an additional 4 cycles of docetaxel were given [25]. Outcome data from this study have been published [22] and recently updated [27] and confirm that patients who achieved a pCR have an improved DFS and OS compared with patients who do not, although for the study group as a whole there was no difference in OS and a trend towards an increased DFS in women who received the taxane prior to surgery as opposed to after. Interestingly, the meta-analysis by De Laurentiis et al. [24] showed that the pooled hazard ratio was 0.83 (95\% CI $0.79-0.87 ; P<0.00001)$ for DFS and 0.85 (95\% CI $0.79-0.91 ; P<0.00001)$ for OS for inclusion of a taxane in the regimen. This meta-analysis, however, did not include the results from the more recently published TACT study comparing a sequential taxanecontaining regimen with a standard anthracyclinecontaining regimen in the adjuvant setting in 4162 women where no disease-free or survival advantage was found after a median follow-up of 62 months [28].

For comparison, the hazard ratios obtained from a Cox regression analysis of this study are 0.79 (95\% CI $0.56-$ $1.12 ; P=0.18)$ for DFS and 0.81 (95\% CI $0.60-1.09$; $P=0.17)$ for OS.
Balancing DFS and OS advantages from sequential versus concurrent administration with taxanes also needs to take the safety profile into account. The toxicity and dose intensity from this study has been discussed previously [1], but it should be noted that since our initial publication one study was stopped early because of toxicity in the AD arm using the same doses in an adjuvant setting [29] and another adjuvant study using concurrent anthracyclines and taxanes (TAC vs. FAC), again with the same dose of doxorubicin and docetaxel, was associated with a significant survival advantage ( 87 vs. $81 \%, P=0.008$ ) but with an increased rate of febrile neutropenia in the taxane-containing arm (24.7 vs. $2.5 \%, P=0.001$ ) [30]. The Goldstein study was also associated with an increase in grade 3 neutropenia with fever or infection with $\mathrm{AD}(26$ vs. $10 \%, P<0.05)$ [23]. It is standard practice now to use primary prophylaxis with granulocyte-colony-stimulating factor where the risk of febrile neutropenia is $20 \%$ or more [31]; this will influence the toxicity profiles for current and future regimens.

It is clear that primary chemotherapy can decrease the need for mastectomy and that the $\mathrm{pCR}$ can be increased if a non-cross-resistant regimen is given. Thus, $\mathrm{AD}$ does appear to offer less of an advantage over $\mathrm{AC}$ if the taxane is given concomitantly than if it is given sequentially. Continued evaluation of response rates to particular treatment regimens, including the use of some of the newer targeted therapies, and scheduling will lead to incremental improvements in the pCR and subsequent outcome. As with all aspects of breast cancer, attention is now being paid to defining the value of particular molecular and genetic markers, as well as more sophisticated imaging techniques that will predict for responsiveness as well as non-responsiveness to a variety of novel agents with different mechanisms of action which have been emerging over recent years. 
Of particular interest is that this approach in terms of interpretation of pathologic response underpins the value of the primary medical setting to provide information more quickly on new approaches and new agents but that larger numbers of patients are required to demonstrate small, but potentially meaningful, improvements in overall survival.

Acknowledgements The authors would like to thank all the patients, medical and nursing staff, and the data managers involved in conducting the study together with Helen Brown from Quantics for statistical support. This study was supported by Aventis Pharma, UK and Chugai Pharma UK.

Conflict of interest statement AJ: honoraria for advisory board and consultancy (not related to this study) and sponsorship for travel to San Antonio. TRJE: Chugai supported a commercial study and sponsorship to ASCO meeting. JM: sponsorship for meeting to ASCO, San Antonio. DC: Sanofi-Aventis, Pfizer consultancy (not related to study drugs or study), sponsorship for travel to meetings. JC: Support for travel, educational presentations, Sanofi-Aventis honoraria. RC: honoraria and speakers fees. HE: educational grant from Sanofi-Aventis on other projects. RL: education grant and honoraria from Sanofi-Aventis.

\section{References}

1. Evans TRJ, Yellowlees A, Foster E et al (2005) A phase III randomized trial of doxorubicin and docetaxel versus doxorubicin and cyclophosphamide as primary medical therapy of women with breast cancer: an Anglo-Celtic Co-operative Oncology Group Study. J Clin Oncol 23:2988-2995

2. Bonadonna G, Valagussa P, Zucali R et al (1995) Primary chemotherapy in surgically respectable breast cancer. CA Cancer $\mathrm{J}$ Clin 45:227-243

3. Ellis PA, Smith IE (1996) Primary chemotherapy for early breast cancer. Cancer Treat Rev 22:437-450

4. Mansi JL, Smith IE, Walsh G et al (1989) Primary medical therapy for operable breast cancer. Eur J Cancer Clin Oncol 25:1623-1627

5. Bonadonna G, Valagussa P, Brambilla C et al (1998) Primary chemotherapy in operable breast cancer: 8-year experience at the Milan Cancer Institute. J Clin Oncol 16:93-100

6. Fisher B, Bryant J, Wolmark N et al (1998) Effect of preoperative chemotherapy on the outcome of women with operable breast cancer. J Clin Oncol 16:2672-2685

7. Van der Hage JA, Van de Velde CJH, Julien J-P et al (2001) Preoperative chemotherapy in primary operable breast cancer: results from the European Organization for Research and Treatment of Cancer trial 10902. J Clin Oncol 19:42244237

8. Chollet P, Amat S, Cure H et al (2002) Prognostic significance of a complete pathological response after induction chemotherapy in operable breast cancer. Br J Cancer 86:1041-1046

9. Amat S, Abrial C, Penault-Llorca F et al (2005) High prognostic significance of residual disease after neoadjuvant chemotherapy: a retrospective study in 710 patients with operable breast cancer. Breast Cancer Res Treat 94:255-263

10. Carey LA, Metzger R, Dees EC et al (2005) American Joint Committee on Cancer tumor-node-metastasis stage after neoadjuvant chemotherapy and breast cancer outcome. J Natl Cancer Inst 97:1137-1142
11. Schwartz GF, Cantor RI, Biermann WA (1987) Neoadjuvant chemotherapy before definitive treatment for stage III carcinoma of the breast. Arch Surg 122:1430-1434

12. Clemons M, Leahy M, Valle J et al (1997) Review of recent trials of chemotherapy for advanced breast cancer: The Taxanes. Eur J Cancer 33:2183-2193

13. Valero V, Holmes FA, Walters RS et al (1995) Phase II trial of docetaxel: a new, highly effective antineoplastic agent in the management of patients with anthracycline-resistant metastatic breast cancer. J Clin Oncol 13:2886-2894

14. Misset JL, Dieras V, Gruia G et al (1999) Dose-finding study of docetaxel and doxorubicin in first-line treatment of patients with metastatic breast cancer. Ann Oncol 10:553-560

15. Palmeri S, Leonardi V, Tamburo de Bella M et al (2002) Doxorubicin-docetaxel sequential schedule: results of front-line treatment in advanced breast cancer. Oncology 63:205-212

16. Nabholtz JM, Falkson C, Campos D et al (2003) Docetaxel and doxorubicin compared with doxorubicin and cyclophosphamide as first-line chemotherapy for metastatic breast cancer: results of a randomized, multicentre, phase III trial. J Clin Oncol 21: 968-975

17. Powles TJ, Hickish TF, Makris A et al (1995) Randomized trial of chemoendocrine therapy started before or after surgery for treatment of primary breast cancer. J Clin Oncol 13:547-552

18. Kuerer HM, Newman LA, Smith TL et al (1999) Clinical course of breast cancer patients with complete pathologic primary tumor and axillary lymph node response to doxorubicin-based neoadjuvant chemotherapy. J Clin Oncol 17:460-469

19. Mauriac L, MacGrogan G, Avril A et al (1999) Neoadjuvant chemotherapy for operable breast cancer larger than $3 \mathrm{~cm}$; a unicentre randomized trial with a 124-month median follow up. Institut Bergonie Bordeaux Groupe Sein. Ann Oncol 10: 47-52

20. Pierga JY, Moiret E, Dieras V et al (2000) Prognostic value of persistent node involvement after neoadjuvant chemotherapy in patients with operable breast cancer. Br J Cancer 53:1480-1487

21. Guarneri V, Broglio K, Kau SW et al (2006) Prognostic value of pathologic complete response after primary chemotherapy in relation to hormone receptor status and other factors. J Clin Oncol 24:1037-1044

22. Bear HD, Anderson S, Smith RE et al (2006) Sequential preoperative or postoperative docetaxel added to preoperative doxorubicin plus cyclophosphamide for operable breast cancer. National Surgical Adjuvant breast and Bowel Project. J Clin Oncol 24:2019-2027

23. Goldstein LJ, O'Neill A, Sparano JA et al (2008) Concurrent doxorubicin plus docetaxel is not more effective than concurrent doxorubicin plus cyclophosphamide in operable breast cancer with 0 to 3 positive axillary nodes: North American Breast Cancer Intergroup Trial E 2197. J Clin Oncol 26:4092-4099

24. De Laurentiis M, Cancello G, D'Agostino D et al (2008) Taxanebased combinations as adjuvant chemotherapy of early breast cancer: a meta-analysis of randomized trials. J Clin Oncol 26: 44-53

25. Bear HD, Anderson S, Brown A et al (2003) The effect on tumour response of adding sequential preoperative docetaxel to preoperative doxorubicin and cyclophosphamide: preliminary results from National Surgical Adjuvant Breast and Bowel Project Protocol B-27. J Clin Oncol 21:4165-4174

26. Smith IC, Heys SD, Hutcheon AW et al (2002) Neoadjuvant chemotherapy in breast cancer: significantly enhanced response with docetaxel. J Clin Oncol 20:1456-1466

27. Rastogi P, Anderson SJ, Bear HD et al (2008) Preoperative chemotherapy: updates of National Surgical Adjuvant Breast and Bowel Project Protocols B-18 and B-27. J Clin Oncol 26: 778-785 
28. Ellis P, Barrett-Lee P, Johnson L et al (2009) Sequential docetaxel as adjuvant chemotherapy for early breast cancer (TACT): an open-label, phase III randomized controlled trial. Lancet 16:1681-1692

29. Brain EG, Bachelot T, Serin D et al (2005) Life-threatening sepsis associated with adjuvant doxorubicin plus docetaxel for intermediate-risk breast cancer. JAMA 18:2367-2371
30. Martin M, Pienkowski T, Mackey J et al (2005) Adjuvant docetaxel for node-positive breast cancer. N Engl J Med 2:23022313

31. Smith TJ, Khatcheressian J, Lyman GH et al (2006) 2006 update of recommendations for the use of white blood cell growth factors: an evidence-based clinical practice guideline. J Clin Oncol 24:3187-3205 